\title{
Modeling of Breakthrough Curves for Removal of Chromium from Waste Water
}

\author{
Dr. Sunil J. Kulkarni ${ }^{1}$, Ankit Mishra ${ }^{2}$, Somesh Patil ${ }^{3}$, Kiran Uphale ${ }^{4}$ \\ ${ }^{1}$ Asstt. Prof., Department of Chemical Engineering, Datta Meghe College of Engineering, Airoli, Navi-Mumbai. \\ ${ }^{2,3,4}$ B.E.Student, Department of Chemical Engineering, Datta Meghe College of Engineering, Airoli, Navi- \\ Mumbai \\ *Corresponding Author: Dr. Sunil J. Kulkarni, Asstt. Prof., Department of Chemical Engineering, Datta \\ Meghe College of Engineering, Airoli, Navi-Mumbai.
}

\begin{abstract}
Abs tract: The development in technology and industrial activities has lead to release of various metal ions to the environment. The present study aims to assess the efficiency of Rice Husk in treating chromium (VI) from simulated wastewater, with the help of fixed-bed adsorption column by performing continuous adsorption experiment. The results obtained through this study were confirmed by developing a model. A detailed analysis on the effects of extensive parameters on the adsorption experiment was done. The extensive parameters considered were Concentration, Flow-rate, and Bed-height. It was observed that as flowrate decreased from $60 \mathrm{ml} / \mathrm{min}$ to $30 \mathrm{ml} / \mathrm{min}$, the breakthrough time also decreased from 30 to $20 \mathrm{~min}$. whereas as when the concentration was increased from $250 \mathrm{mg} / \mathrm{L}$ to $1000 \mathrm{mg} /$, the breakthrough time came down to $10 \mathrm{~min}$ fro $\mathrm{m} 40$ min. The parameters which were calculated were total percentage removal of Cr (VI) and breakthrough time. It was observed that the exhaustion time decreases with increase in the concentration and flow rate and it increases with bed height. The data obtained during the entire experiment were fitted in Thomas and Yoon Nelson Model. The values of the model parameters were evaluated and analyzed.
\end{abstract}

Keywords: Adsorption, flow rate, concentration, break through curve, model parameters

\section{INTRODUCTION}

Water pollution has been a great concern worldwide due to the disposal of heavy metals. Waste effluent from numerous industries contains toxic elements such as heavy metals like $\mathrm{Pb}, \mathrm{Cr}, \mathrm{Zn}, \mathrm{Cu}, \mathrm{Ni}$, and $\mathrm{Fe}$. When these toxic heavy metals interact with the eco-system, there is a high possibility that they may also accumulate in the human body through direct intake or either through food chain. This accumulation even in micro quantity may lead to severe physiological and neurological damage. Hence measures must be taken to prevent these metals from entering the natural environment [2]. Taking into account the problems caused by these toxic metals to the humans as well as to the environment, their removal from waste water is a very serious concern [3]. Various me thods for the removal of these heavy metals, both economical and non-economical are available. The non-economical methods and the conventional methods are Ion Exchange, Chemical Precipitation, Solvent Extraction, Membrane Process, Electrodialysis \& Reverse Osmosis. There are many disadvantages of these methods including incomplete metal removal, high energy consumption. These methods generate toxic sludge that further requires proper disposal and treatment [4]. The Economical method is Biosorption. It is a physiochemical process that utilizes less low cost biosorbent. This process occurs naturally in some biomass [5]. Biosorption has many advantages over the conventional methods like low operating cost, short operation time, no chemical sludge, reusability of biomaterial. Vigorous attempts have been taken in order to use agricultural waste which is easy to obtain and also cheap such as Rice Husk, Groundnut Shell and many others as a bio-adsorbent for the removal of toxic metals from the waste water [1]. Recently there has been an increase in the use of biomass for the cleaning up of environment, Scientist and engineer are expecting that use of bio-adsorbent for the removal of toxic metals will be an economical option. Rice hulls are there to protect the seeds during growing season as they cover the seeds. Opaline, silica and lignin are present in rice husk. The agricultural waste which comprises of groundnut shell, peanut shell, rice hull comes under the species ArachishypogaeaL. They have huge potential to isolate heavy metals from the water $[6,7]$. The study is mainly based on identifying the potential of rice husk in removing heavy metals from the wastewater. 


\section{MATERIAL AND METHOD}

\subsection{Adsorbent Preparation}

Rice husk is an agricultural waste and is used as low cost adsorbent. It was obtained from a local paddy mill[8]. The rice husk was heated to remove other impurities.After heating the rice husk was washed with Distilled Water and $\mathrm{HCl}$. Further the rice husk was kept in an oven at $100^{\circ} \mathrm{C}$ for an hour; the water present in rice husk was removed

\subsection{Adsorbate Preparation}

The simulated stock solution was prepared by dissolving $1.414 \mathrm{~g}$ of Potassium Dichromate $\left(\mathrm{K}_{2} \mathrm{Cr}_{2} \mathrm{O}_{7}\right)$ in $1000 \mathrm{ml}$ of distilled water. In stock solution we had $1 \mathrm{ml}$ equivalent to $500 \mu \mathrm{gm}$ Cr. Further the solution of desired concentration (250-1000) $\mathrm{mg} / \mathrm{Lwas}$ prepared by diluting the stock solution with distilled water.

\subsection{Reagent Pre paration}

Diphenyl Carbazidereagent was prepared by dissolving $0.04 \mathrm{gm}$ of 1,5-diphenyl Carbazide solution in $20 \mathrm{ml}$ Iso - propyl alcohol, along with it $8 \mathrm{ml}$ of conc. $\mathrm{H}_{2} \mathrm{SO}_{4}$ was added and the solution was diluted to $100 \mathrm{ml}$ by addition of $72 \mathrm{ml}$ of distilled water. This Diphenyl Reagent was then used for the detection process with the help of Spectrophotometer.

\subsection{Expe rimental Studies}

For the removal of toxic $\mathrm{Cr}$ (VI) from the aqueous solution a continuous fixed bed experiment was carried out, wherein activated rice husk was used as a low cost bio-adsorbent. The apparatus consisted of a fixed column of glass with $5 \mathrm{~cm}$ internal diameter. The stock solution of $\mathrm{Cr}$ (VI) was made to pass through the column in a down flow mode. The flow was maintained by a valve. The parameters including flow rate, mass of adsorbent (bed-height), and inlet $\mathrm{Cr}$ (VI) concentration were varied during this study. The flow rate was maintained constant using a valve $(30-60 \mathrm{~mL}$ min-1). The method used for analyzing the quantity of $\mathrm{Cr}(\mathrm{VI})$ in the aqueous solution was Di-Phenyl carbazide. This method only indicates the quantity of $\mathrm{Cr}(\mathrm{VI})$ in the aqueous solution. At low $\mathrm{pH}$ this method has been used widely in various studies [9]. A purple-voilet color was developed when Di-Phenyl Carbazide reagent was added to the effluent collected from the experiment Further UV-Spectrophotometer was used for the analysis of the concentration of $\mathrm{Cr}$ (VI) ions in the effluent. Di-Phenyl Carbazide Reagent over here works as a complexing agent. The absorbance of the effluent after addition of the reagent was mea sured at a wavelength of $540 \mathrm{~nm}$. With the help of calibration curve the deviation in the concentration of $\mathrm{Cr}$ (VI) was obtained.

\section{Mathematical Modeling and Simulation}

\subsection{Thomas Model}

An expression for adsorption column by Thomas is given by following equation

$\frac{\mathrm{C}}{\mathrm{C}_{0}}=\frac{1}{1+\exp \left[\frac{\mathrm{Kt}}{\mathrm{Q}\left(\mathrm{q}_{0} \mathrm{M}-\mathrm{C}_{0} \mathrm{~V}\right)}\right]}$

In the equation (1), $\mathrm{C}$ is the outlet concentration at any time $\mathrm{t}$ and $\mathrm{Co}$ is inlet concentration. $\mathrm{V}$ is throughput volume, $\mathrm{Q}$ volumetric flow rate, $\mathrm{K}_{\mathrm{t}}$ is Thomas constant and $\mathrm{q}_{0}$ is maximum adsorption capacity. [11]

The linear form of this equation is written as

$$
\ln \left(\frac{\mathrm{C}_{0}}{\mathrm{C}}-1\right)=\frac{\mathrm{K}_{\mathrm{t}} \mathrm{q}_{0} \mathrm{M}}{\mathrm{Q}}-\mathrm{k}_{\mathrm{t}} \mathrm{C}_{0} \mathrm{t}
$$

The plot of $\ln \left(\frac{C_{0}}{C}-1\right)$ against $t$ is a straight-line. The values of the parameters $\mathrm{K}_{\mathrm{t}}$, and $\mathrm{q}_{0}$ are estimated from this plot.

\subsection{Yoon and Nelson Model}

Yoon and Nelson developed a model based on the assumption that the rate of decrease in the probability of adsorption of adsorbate molecule is proportional to the probability of the adsorbate adsorption and the adsorbate breakthrough on the adsorbent [12]. 
This model is expressed by following equation

$\frac{\mathrm{C}}{\mathrm{C} 0}=\frac{1}{1+\exp [\mathrm{K}(\mathrm{T}-\mathrm{t})]}$

$\ln \frac{\mathrm{C}}{\mathrm{C}_{0}-\mathrm{C}}=\mathrm{kt}-\mathrm{Tk}$

Here, $\mathrm{k}$ is the rate constant and $\mathrm{T}$ is time required for 50 percent adsorbate breakthrough and $\mathrm{t}$ is sampling time in the equation (3)\&(4). The plot of $\ln \left(\frac{C}{C_{0}-C}\right)$ against time is plotted. The parameters, T and $\mathrm{k}$ are obtained from the plot.

\section{RESULT}

\subsection{Effect of Concentration}

Detailed studies on the change of sorption capacity with time for different initial concentrations have been done in order to evaluate the sorption characteristics of Rice Husk for $\mathrm{Cr}$ ions. A series of experiments were undertaken by varying the initial $\mathrm{Cr}$ concentration in the range of $250 \mathrm{mg} / \mathrm{L}, 500$ $\mathrm{mg} / \mathrm{L}, 1000 \mathrm{mg} / \mathrm{L}$ on the removal of $\mathrm{Cr}$ from the simulated solution. It has been found that as the concentration increases the adsorption capacity also increases and the breakthrough point is obtained earlier. The optimum concentration was found to be $1000 \mathrm{mg} / \mathrm{L}$. At this concentration the removal was $78.95 \%$ after $10 \mathrm{~min}$, whereas for concentration of $250 \mathrm{mg} / \mathrm{l} \& 500 \mathrm{mg} / \mathrm{l}$ it was found to be $55.65 \%$ \& $20.97 \%$ respectively. So, the Rice Husk can be used in the industry effluent samples for higher concentrations of chromium. The values of $\mathrm{K}_{\mathrm{t}}$ and $\mathrm{q}_{0}$ were obtained from the graph and it was observed that as concentration was increased the value of $\mathrm{R}^{2}$ also increased from 0.77 to 0.89 .

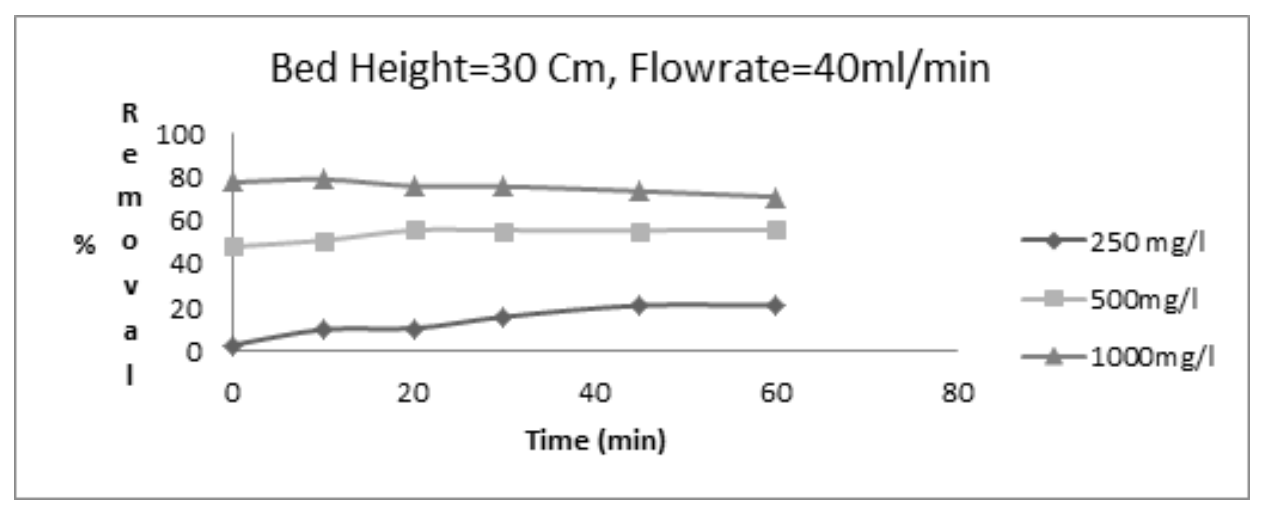

Fig4.1.1. Effect of Concentration on Cr Adsorption

Table1. Effect of Initial Concentration for Thomas Model

\begin{tabular}{|l|r|r|r|}
\hline Parameters & \multicolumn{3}{|c|}{ Concentration at fixed bed height, $\mathrm{pH}$ and flow rate (mg/l) } \\
\hline & 250 & 500 & 1000 \\
\hline $\mathrm{K}_{\mathrm{t}}(\mathrm{ml} / \mathrm{min} / \mathrm{mg})$ & -0.00013 & $-9.6 \mathrm{E}-06$ & $6.5 \mathrm{E}-06$ \\
\hline $\mathrm{q}_{0}(\mathrm{mg} / \mathrm{g})$ & 7542.724 & -4131653 & 67552.68 \\
\hline $\mathrm{R}^{2}$ & 0.7795 & 0.6562 & 0.8922 \\
\hline
\end{tabular}

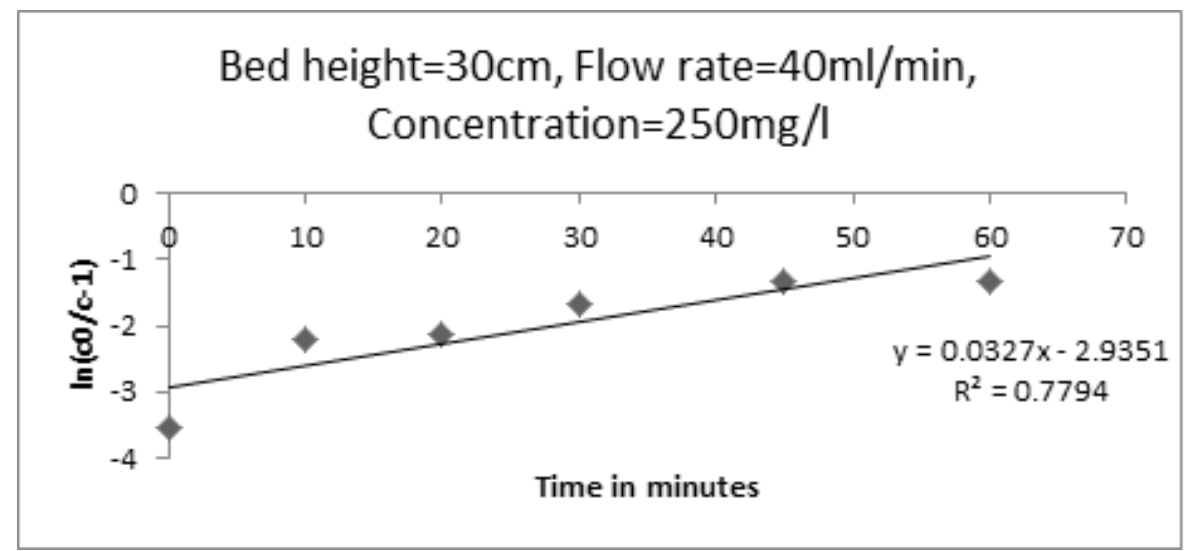

Fig4.1.2. Thomas Model atInitial Concentration of $250 \mathrm{mg} / \mathrm{l}$ 


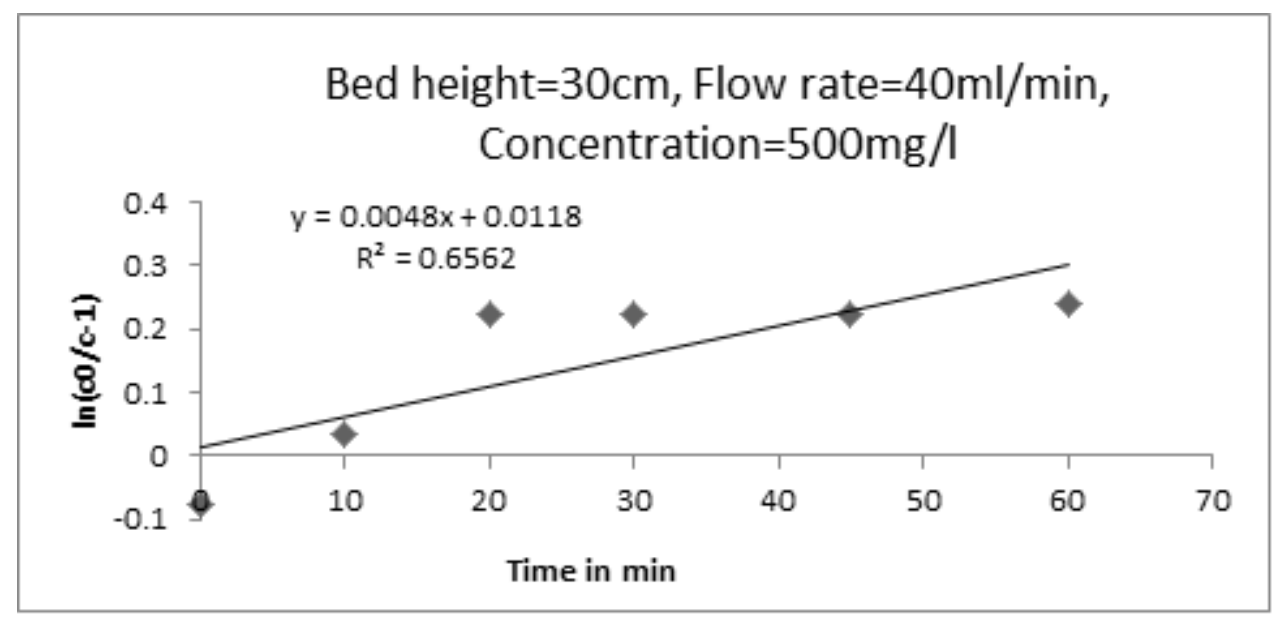

Fig4.1.3. Thomas Model atInitial Concentration of $500 \mathrm{mg} / \mathrm{l}$

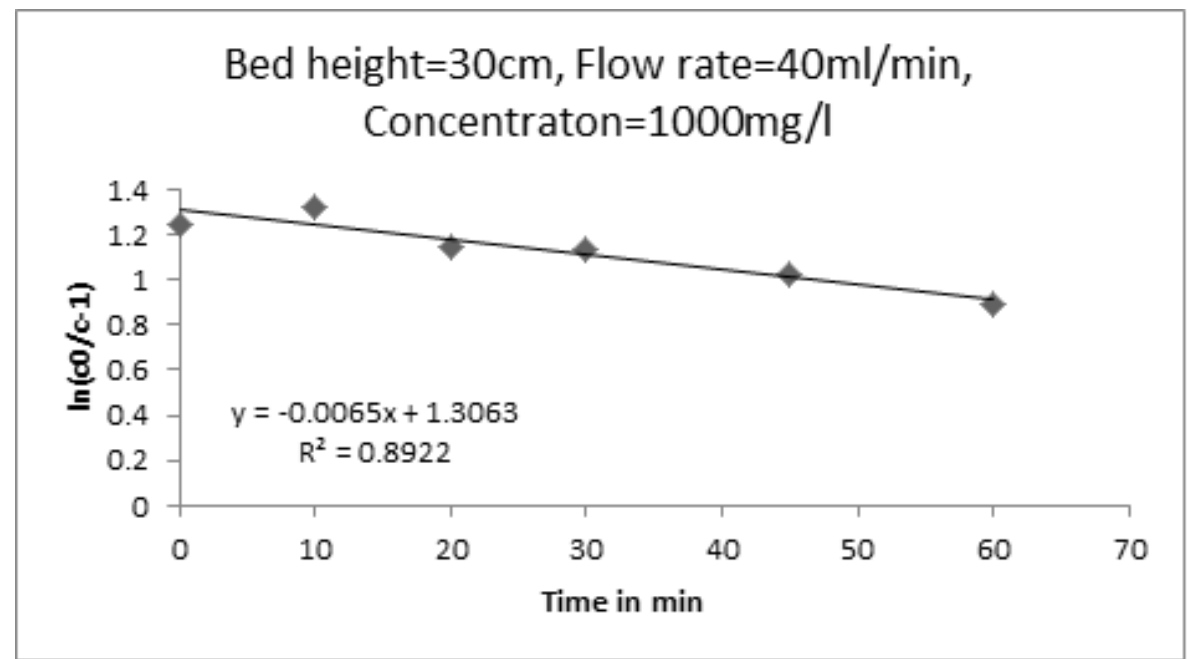

Fig4.1.4. Thomas Model atInitial Concentration of $1000 \mathrm{mg} / \mathrm{l}$

Table2. Effect of Initial Concentration for Yoon Nelson Model

\begin{tabular}{|l|r|r|r|}
\hline Parameters & \multicolumn{3}{|c|}{ Concentration at fixed bed height, $\mathrm{pH}$ and flow rate $(\mathrm{mg} / \mathrm{l})$} \\
\hline $\mathrm{K}(/ \mathrm{min}-1)$ & 250 & 500 & 1000 \\
\hline $\mathrm{T}(\mathrm{min})$ & -0.0327 & -0.0048 & 0.0065 \\
\hline $\mathrm{R}^{2}$ & 89.75841 & -3.75 & 200.9692 \\
\hline
\end{tabular}

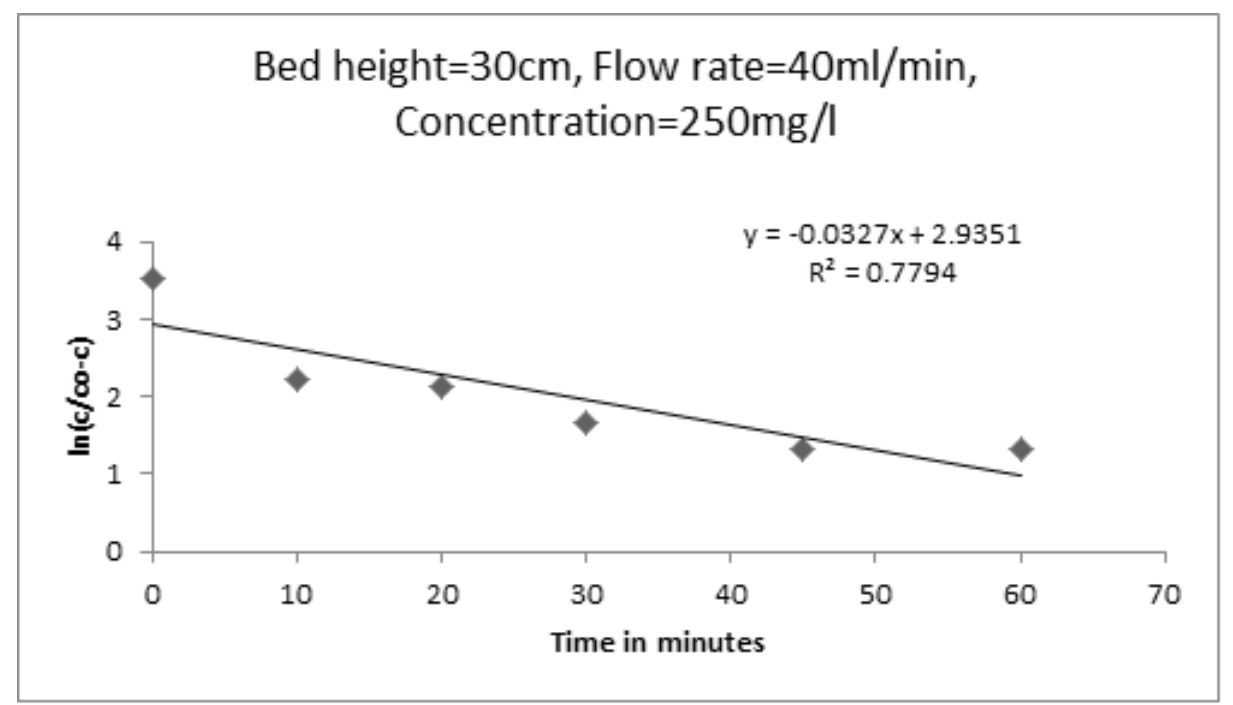

Fig4.1.5. Yoon Nelson Model at Initial Concentration of $250 \mathrm{mg} / \mathrm{l}$ 


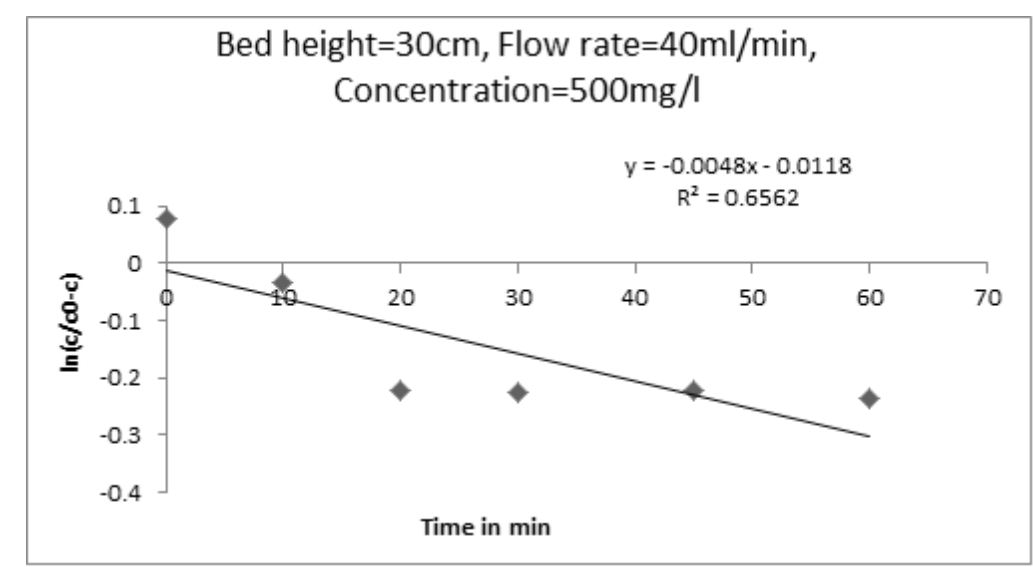

Fig4.1.5. Yoon Nelson Model at Initial Concentration of 500mg/l

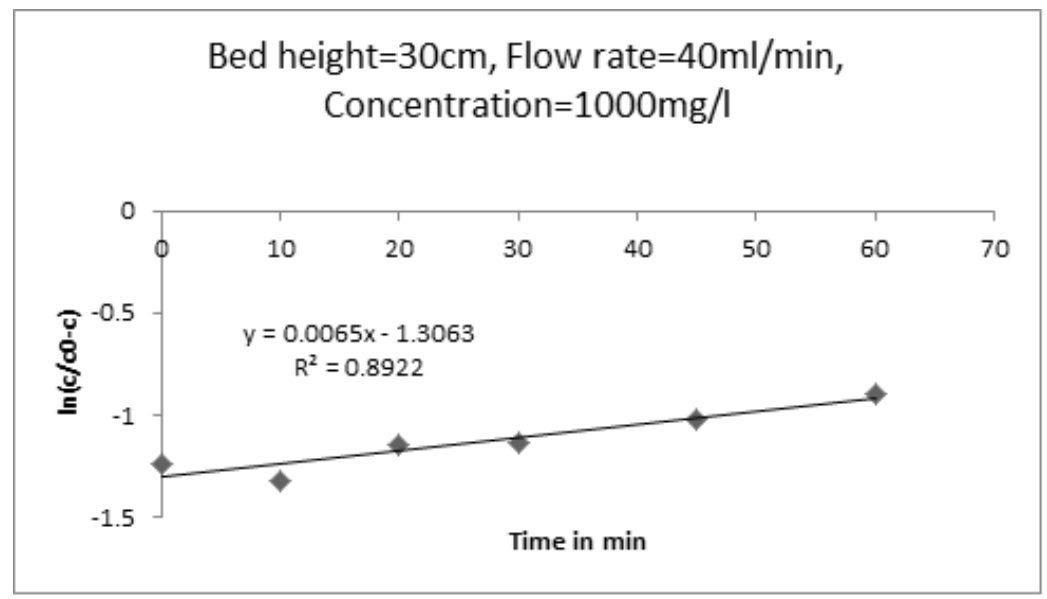

Fig4.1.7. Yoon Nelson Model at Initial Concentration of $1000 \mathrm{mg} / \mathrm{l}$

\subsection{Effect of Concentration ( $\mathrm{C} / \mathrm{CO})$}

The study $\mathrm{Cr}$ concentration at different time intervals has been carried out. A series of experiments were undertaken by varying the initial $\mathrm{Cr}$ concentration in the range of $(250 \mathrm{mg} / \mathrm{L}-1000 \mathrm{mg} / \mathrm{L})$. For 1000 $\mathrm{mg} / \mathrm{L}$, initially the $\mathrm{Cr}$ concentration was low and once bed gets saturated it has increased. At zero time $\mathrm{C} / \mathrm{C}_{0}$ ratio was 0.223 and is decreased to 0.21 at time $10 \mathrm{~min}$. Further $\mathrm{C} / \mathrm{C}_{0}$ ratio was increased to 0.29 after one hour; this is due to the fact that the bed was exhausted. It can be concluded that at $1000 \mathrm{mg} / \mathrm{L}$ the removal was optimum and concentration of $\mathrm{Cr}$ was less.

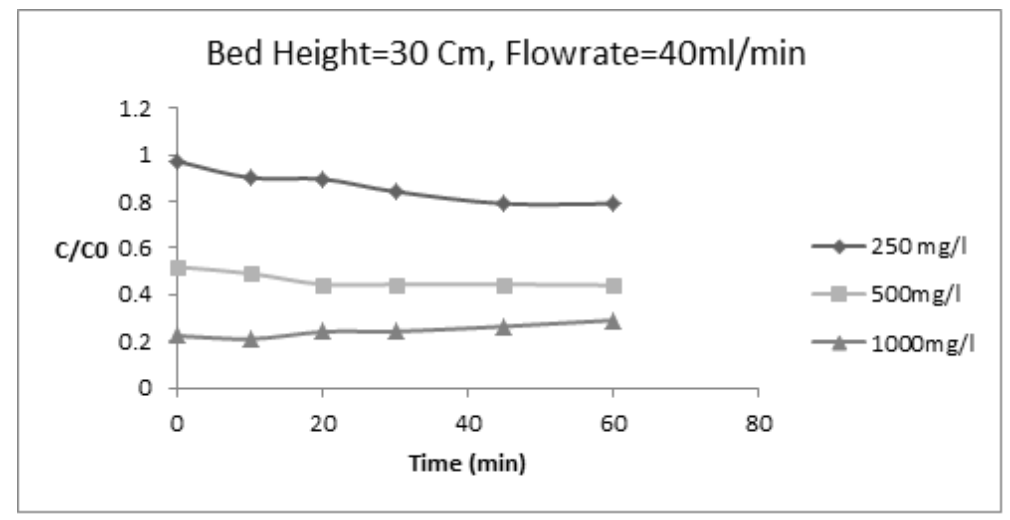

Fig4.2.1. Effect of Concentration $\left(C / C_{0}\right)$

\subsection{Effect of Flow Rate (\% removal vs. time)}

An investigation was carried out on the effect of the flow rate on the adsorption of $\mathrm{Cr}$ by varying the flow rate, with a constant adsorbent bed height of $30 \mathrm{~cm}$ and the initial concentration of $250 \mathrm{mg} / \mathrm{l}$. series of experiments were undertaken by varying the flow rates in the range of $(30 \mathrm{ml} / \mathrm{min}-60 \mathrm{ml} / \mathrm{min})$ i.e. $30 \mathrm{ml} / \mathrm{min}, 40 \mathrm{ml} / \mathrm{min} \& 60 \mathrm{ml} / \mathrm{min}$ simulated solution. It has been found that as flow rate increases the 
adsorption capacity also increases. The optimum flowrate was found to be $30 \mathrm{ml} / \mathrm{min}$. At this flow rate the removal of $\mathrm{Cr}$ was maximum i.e. $72 \%$ after $22 \mathrm{~min}$. Whereas with flow rates $40 \mathrm{ml} / \mathrm{min} \& 60 \mathrm{ml} / \mathrm{min}$ the removal was $63 \%$ \& $55 \%$ respectively. So, the Rice Husk can be used in the industry effluent samples with lower possible flowrates. It has been observed that as the flow rate increased the breakpoint time decreased, also the total adsorbed quantity of $\mathrm{Cr}$ also decreased simultaneously. The reason for this behavior is the insufficient residence time of solute $(\mathrm{Cr})$ in the column. It can be concluded that residence time decreases with increase in the flow rate resulting in insufficient residence time for the diffusion of $\mathrm{Cr}$. The values of $\mathrm{K}_{\mathrm{t}}$ and $\mathrm{q}_{0}$ were obtained from the graph for both the models. The value of $\mathrm{R}^{2}$ for Thomas model was found to be maximum for the flow rate of $40 \mathrm{ml} / \mathrm{min}$, whereas for Yoon \& Nelson model it was found to be maximum for flowrate of $30 \mathrm{ml} / \mathrm{min}$

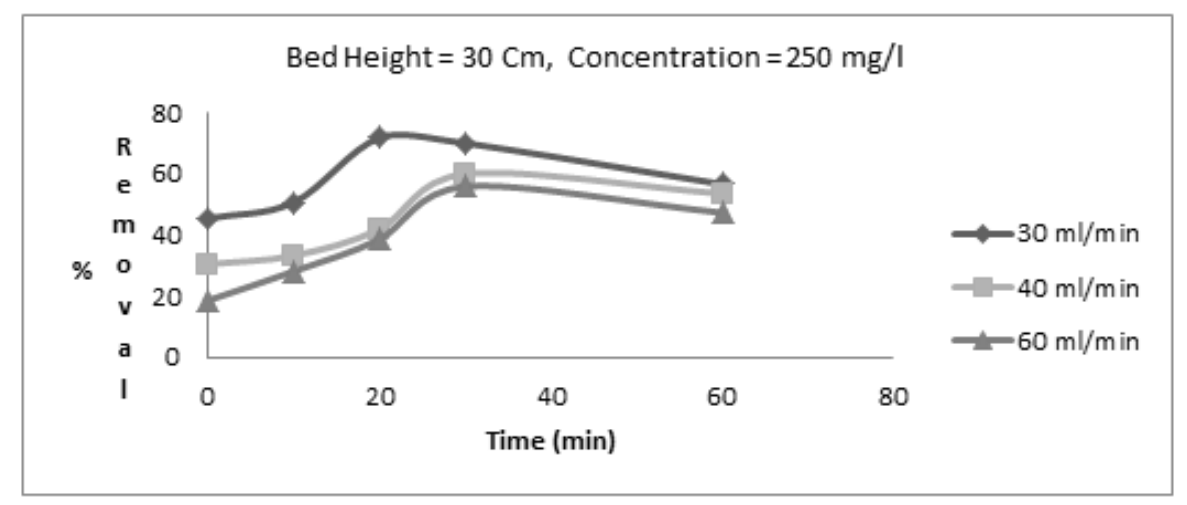

Fig4.3.1. Effect of Flow rate on Cr Adsorption

Table3. Effect of Flow Rate for Thomas Model

\begin{tabular}{|l|r|r|r|}
\hline Parameters & \multicolumn{3}{|c|}{ Flow rate at fixed bed height \& concentration $(\mathrm{ml} / \mathrm{min})$} \\
\hline & 30 & 40 & 60 \\
\hline $\mathrm{K}_{\mathrm{t}}(\mathrm{ml} / \mathrm{min} / \mathrm{mg})$ & -0.00014 & -0.00011 & $-5.5 \mathrm{E}-05$ \\
\hline $\mathrm{q}_{0}(\mathrm{mg} / \mathrm{g})$ & 2339.927 & 2575.978 & -885.113 \\
\hline $\mathrm{R}^{2}$ & 0.7655 & 0.7675 & 0.2309 \\
\hline
\end{tabular}

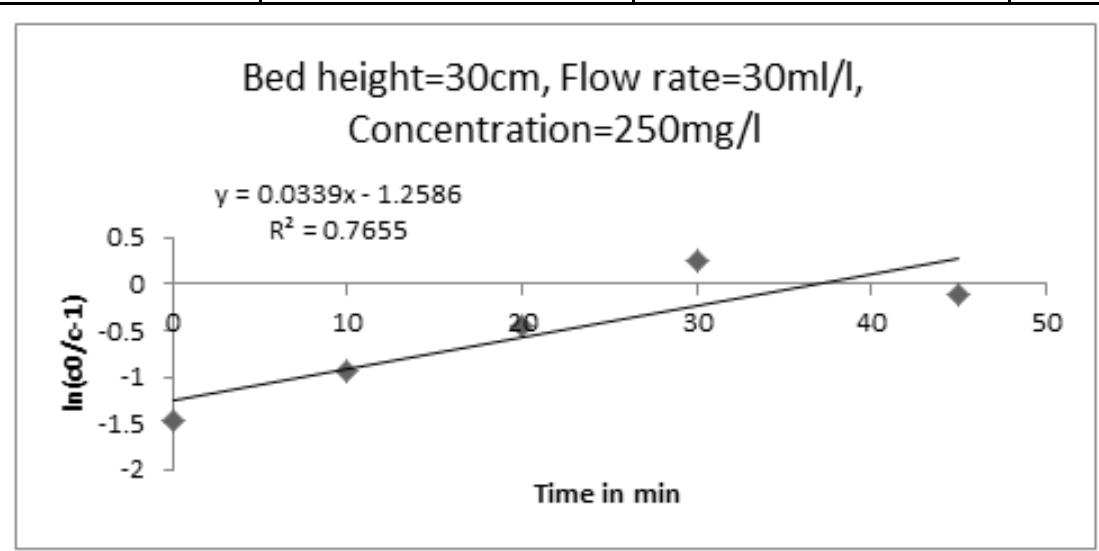

Fig4.3.2. Thomas Model at flow rate of $30 \mathrm{ml} / \mathrm{min}$

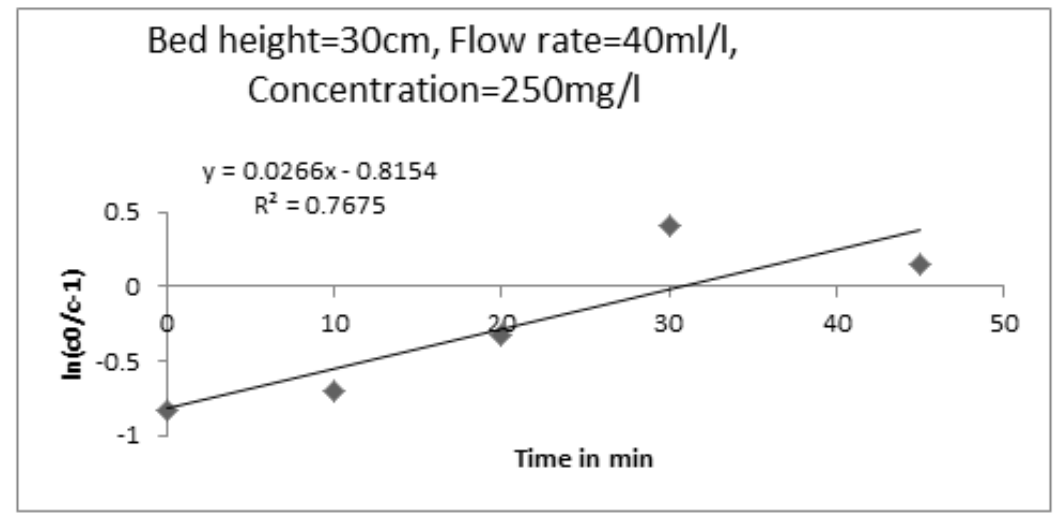

Fig4.3.3. Thomas Model at flow rate of $40 \mathrm{ml} / \mathrm{min}$ 


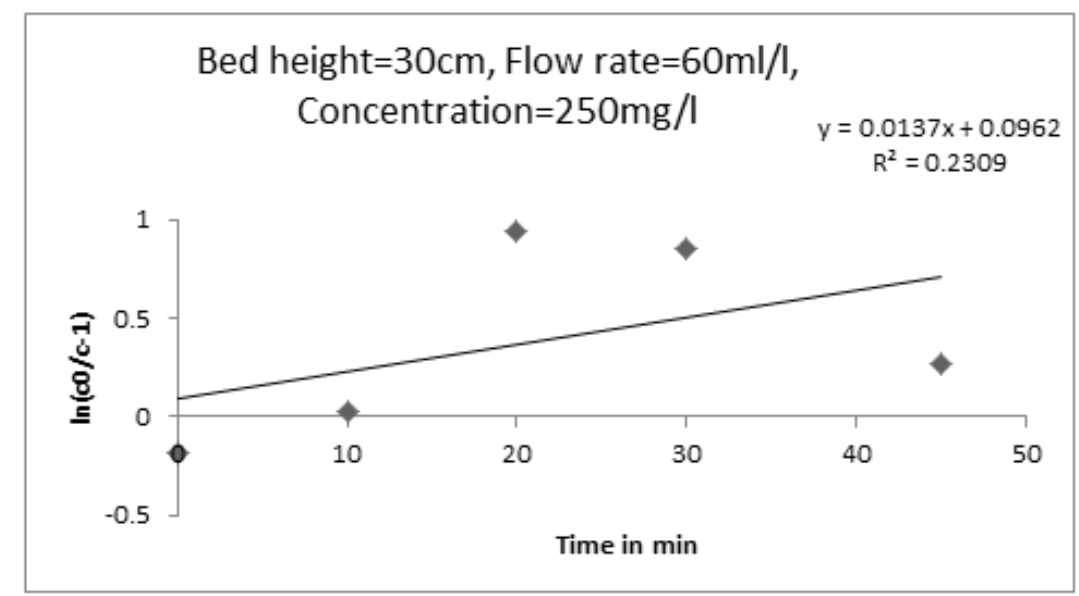

Fig4.3.4. Thomas Model at flow rate of $60 \mathrm{ml} / \mathrm{min}$

Table4. Effect of Flow rate for Yoon Nelson Model

\begin{tabular}{|l|r|r|r|}
\hline Parameters & \multicolumn{3}{|c|}{ Flow rate at fixed bed height \& concentration (ml/min) } \\
\hline $\mathrm{K}(/ \mathrm{min}-1)$ & 30 & 40 & 60 \\
\hline $\mathrm{T}(\mathrm{min})$ & -0.034 & -0.0264 & -0.015 \\
\hline $\mathrm{R}^{2}$ & 37.72941 & 31.33333 & -3.91333 \\
\hline
\end{tabular}

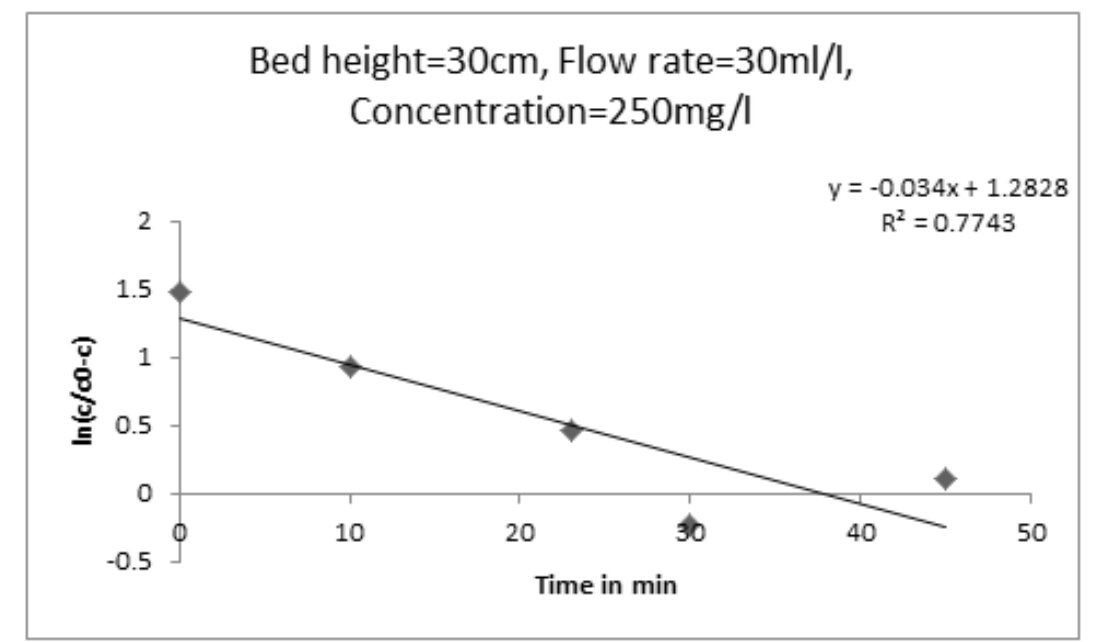

Fig4.3.5. Yoon \& Nelson at flow rate of $30 \mathrm{ml} / \mathrm{min}$

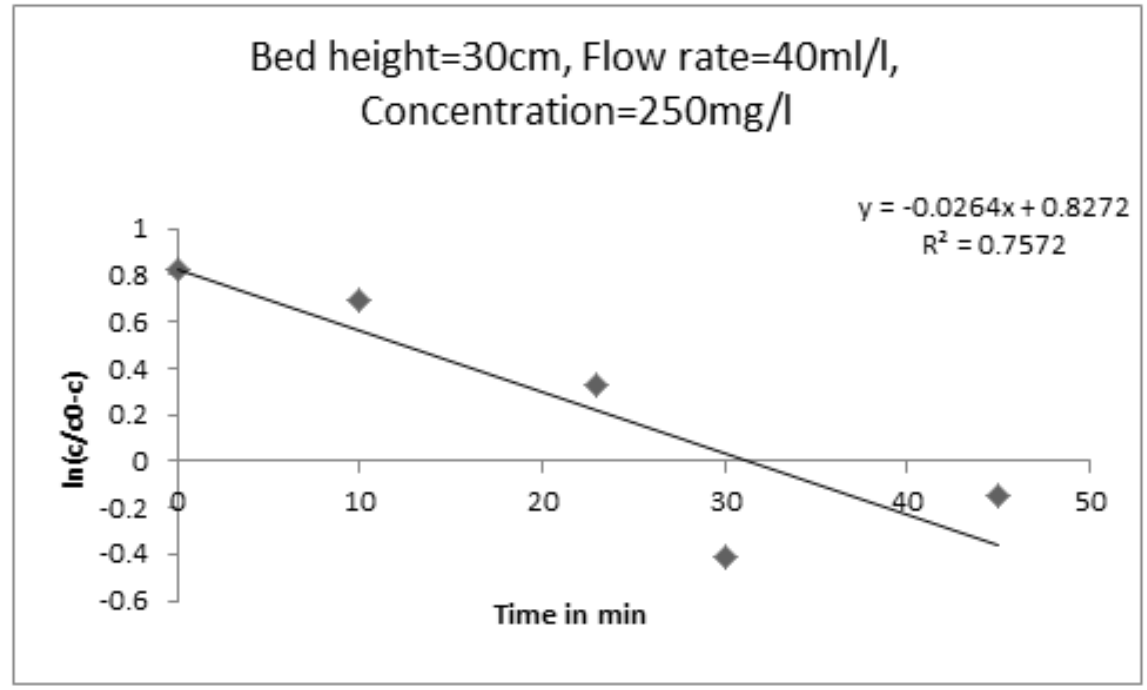

Fig4.3.6. Yoon \& Nelson at flow rate of $40 \mathrm{ml} / \mathrm{min}$ 


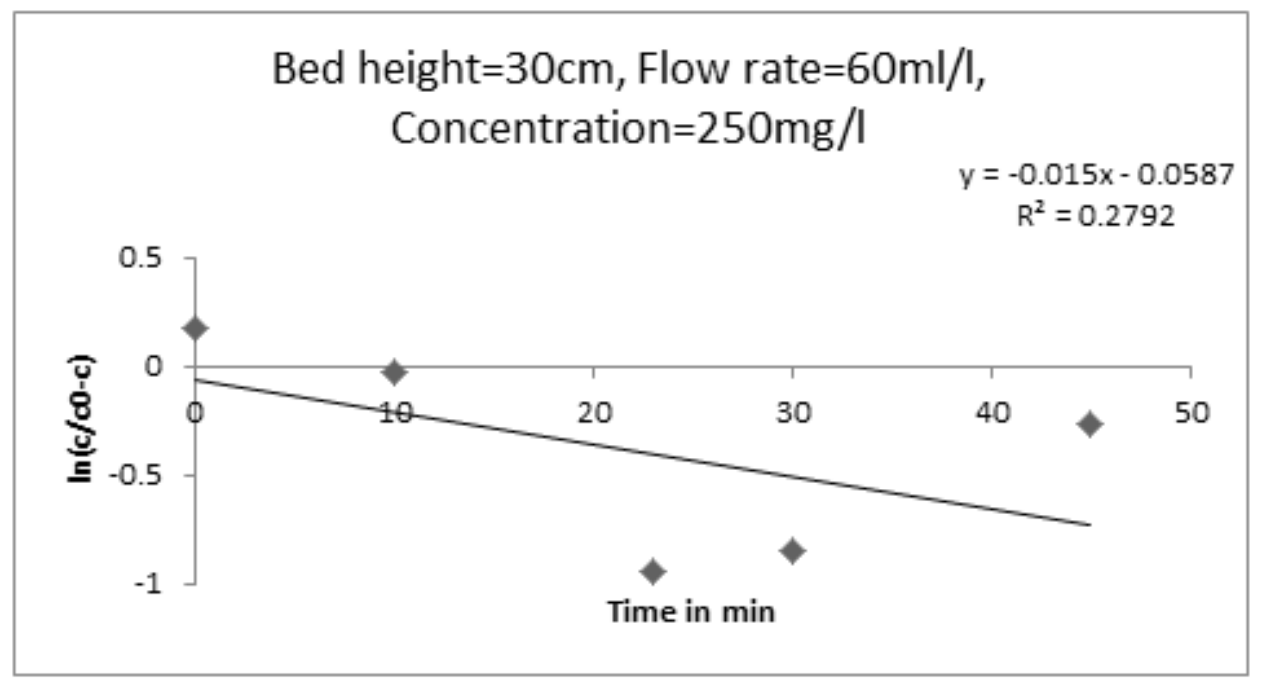

Fig4.3.7. Yoon \& Nelson at flow rate of $60 \mathrm{ml} / \mathrm{min}$

\subsection{Effect of Flow Rate (C/CO vs. Time)}

The effect of the flow rate on change in concentration of $\mathrm{Cr}$ with initial value was investigated by varying the flow rate with a constant adsorbent bed height of $30 \mathrm{~cm}$ and the initial concentration of 250 $\mathrm{mg} / \mathrm{l}$. series of experiments were undertaken by varying the flow rates in the range of $(30 \mathrm{ml} / \mathrm{min}$ $60 \mathrm{ml} / \mathrm{min}$ )i.e. $30 \mathrm{ml} / \mathrm{min}, 40 \mathrm{ml} / \mathrm{min} \& 60 \mathrm{ml} / \mathrm{min}$ simulated solution. It has been found that as flow rate increases initially capacity of removal of Cr was very rapid further after saturation of bed it decreased. At flow rate $60 \mathrm{ml} / \mathrm{min}$ initially c/co ratio was 0.55 at zero time, then it decreased to 0.28 at $20 \mathrm{~min}$.as bed get saturated the value again increased. At $60 \mathrm{~min}$ it again reached to 0.46 . We can conclude that with increase in flow rate, initially $\mathrm{Cr}$ concentration decreases and then it increases again after breakpoint time.

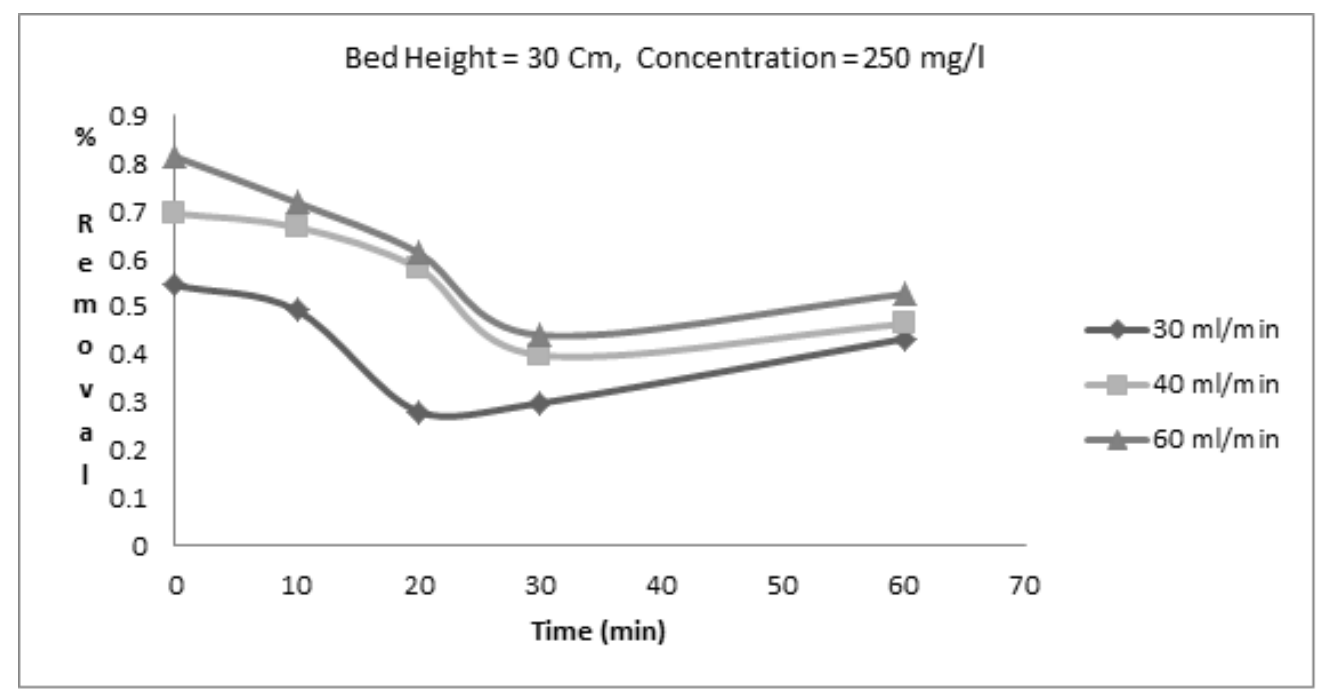

Fig4.4. Effect of Flow rate $\left(\mathrm{C} / \mathrm{C}_{0}\right)$

\subsection{Effect of Bed Height (\% removal vs. time)}

The bio-adsorbent used in packed bed influences the removal capacity of metal ions. Numbers of experiments were carried out for three different bed heights $25 \mathrm{~cm}, 30 \mathrm{~cm}$ and $35 \mathrm{~cm}$ using $92 \mathrm{gm}$, $119 \mathrm{gm}, \& 150 \mathrm{gm}$ of biomass respectively. Concentration and flow rate were fixed at $1000 \mathrm{mg} / \mathrm{l}$ and 40 $\mathrm{ml} / \mathrm{min}$ respectively. Fig 4.5.1 and 4.6 represents the removal of $\mathrm{Cr}$ for various bed heights. It was observed that with increasing bed height removal of metal ions was higher until the bed gets saturated. As the bed height increases the contact time also increases and this results in increase in the \% removal of chromium. Maximum removal obtained at $35 \mathrm{~cm}$ bed height. For $35 \mathrm{~cm}$ bed height initially the removal was about $70.12 \%$ which further increased to $78.22 \%$, which was the maximum removal amongst various bed heights. The values of $\mathrm{K}_{\mathrm{t}}$ and $\mathrm{q}_{0}$ were obtained from the graph. 


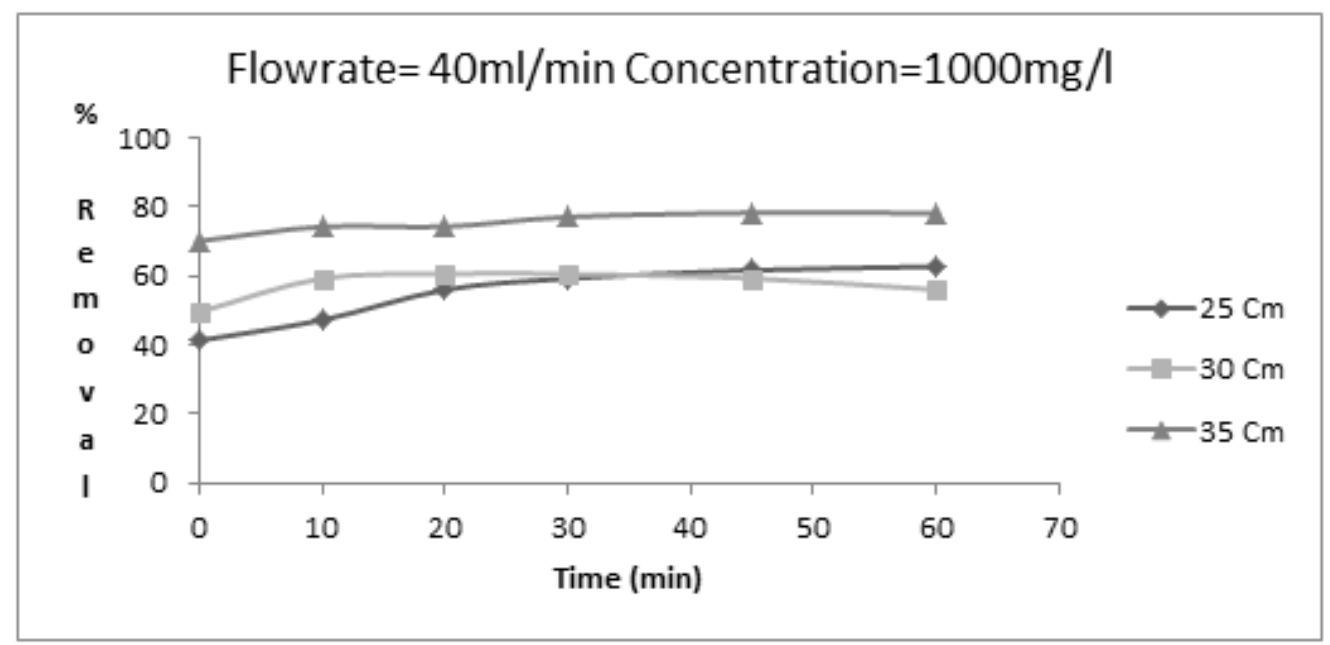

Fig4.5.1. Effect of Bed height on Cr Adsorption

Table5. Effect of Bed Height for Thomas Model

\begin{tabular}{|l|r|r|r|}
\hline Parameters & \multicolumn{3}{|c|}{ Bed height at fixed Flow rate \& concentration $(\mathrm{ml} / \mathrm{min})$} \\
\hline & 25 & 30 & 35 \\
\hline $\mathrm{K}_{\mathrm{t}}(\mathrm{ml} / \mathrm{min} / \mathrm{mg})$ & -0.0000145 & -0.0000025 & -0.0000041 \\
\hline $\mathrm{q} 0(\mathrm{mg} / \mathrm{g})$ & 6227.88606 & -31811.765 & -70465.041 \\
\hline $\mathrm{R} 2$ & 0.852 & 0.1053 & 0.7313 \\
\hline
\end{tabular}

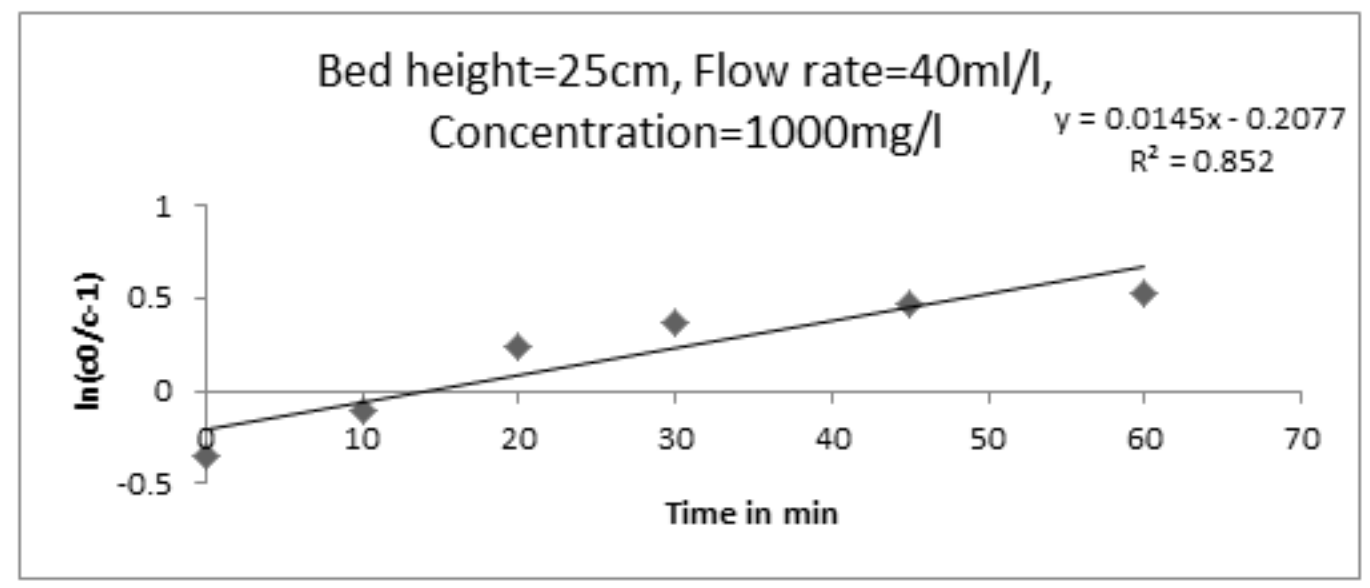

Fig4.5.2. Thomas Model for bed height of $25 \mathrm{~cm}$

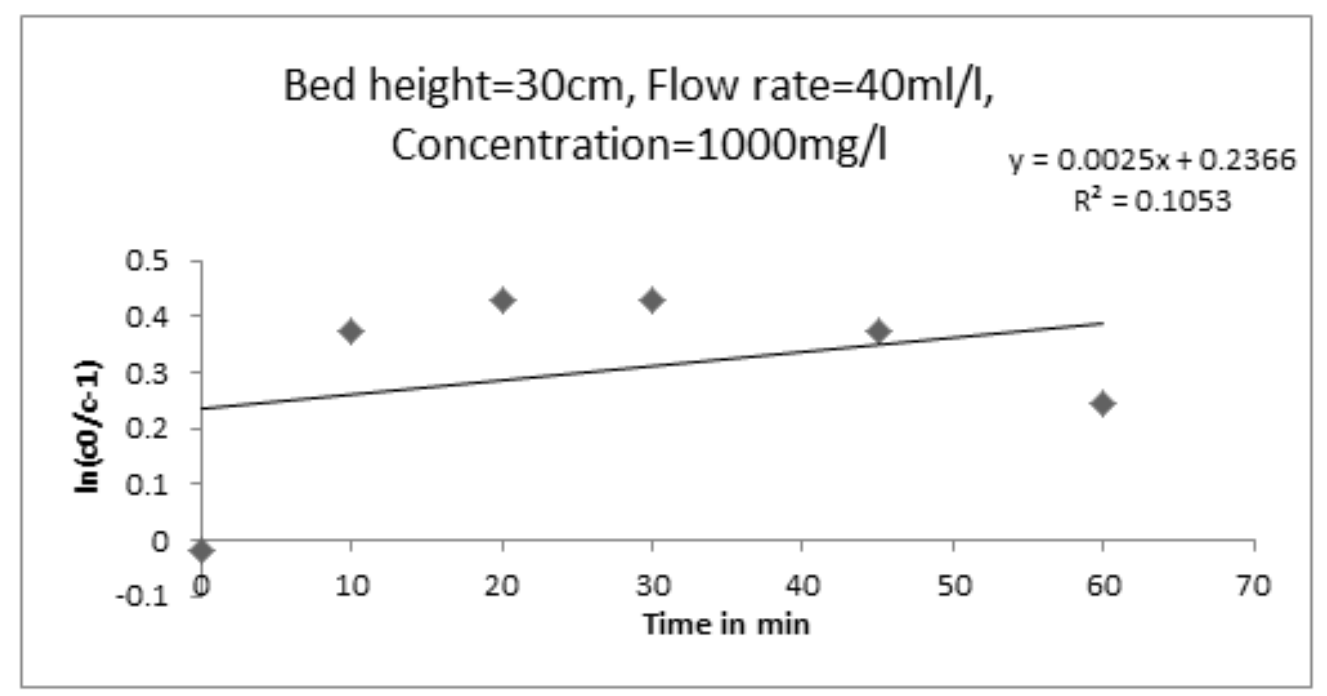

Fig4.5.3. Thomas Model for bed height of $30 \mathrm{~cm}$ 


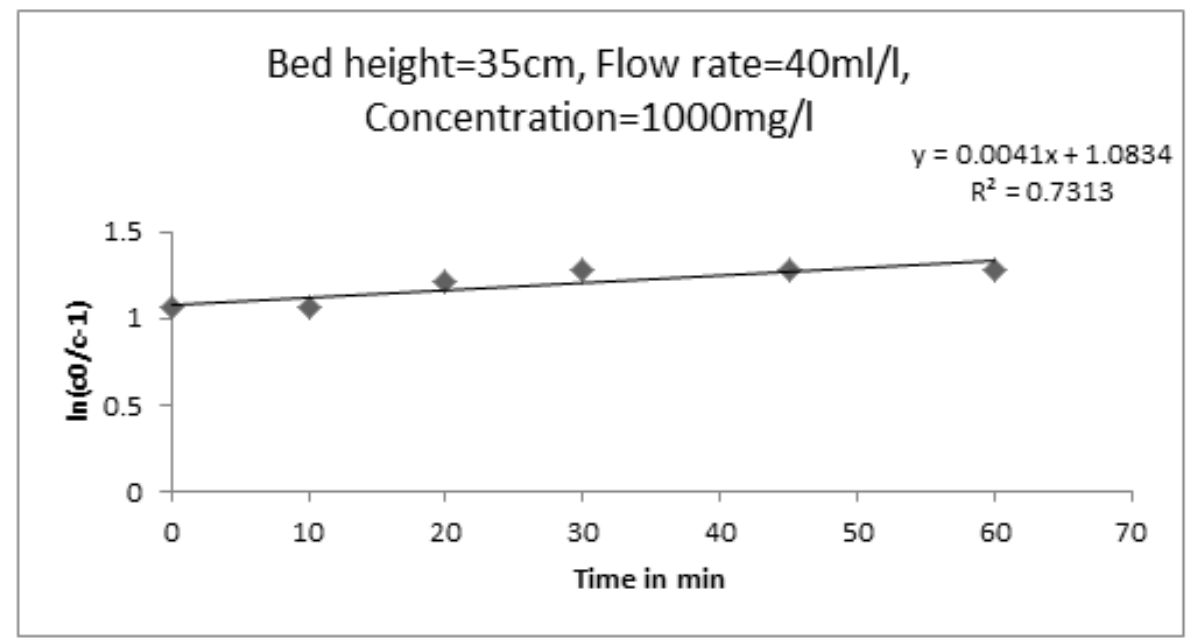

Fig4.5.4. Thomas Model for bed height of $35 \mathrm{~cm}$

Table6. Effect of Bed Height for Yoon Nelson Model

\begin{tabular}{|l|r|r|r|}
\hline Parameters & \multicolumn{3}{|c|}{ Bed height at fixed Flow rate \& concentration $(\mathrm{ml} / \mathrm{min})$} \\
\hline $\mathrm{K}(/ \mathrm{min}-1)$ & 25 & 30 & 35 \\
\hline $\mathrm{T}(\mathrm{min})$ & -0.0145 & -0.0025 & -0.0069 \\
\hline $\mathrm{R}^{2}$ & 14.32414 & -94.64 & -135.841 \\
\hline
\end{tabular}

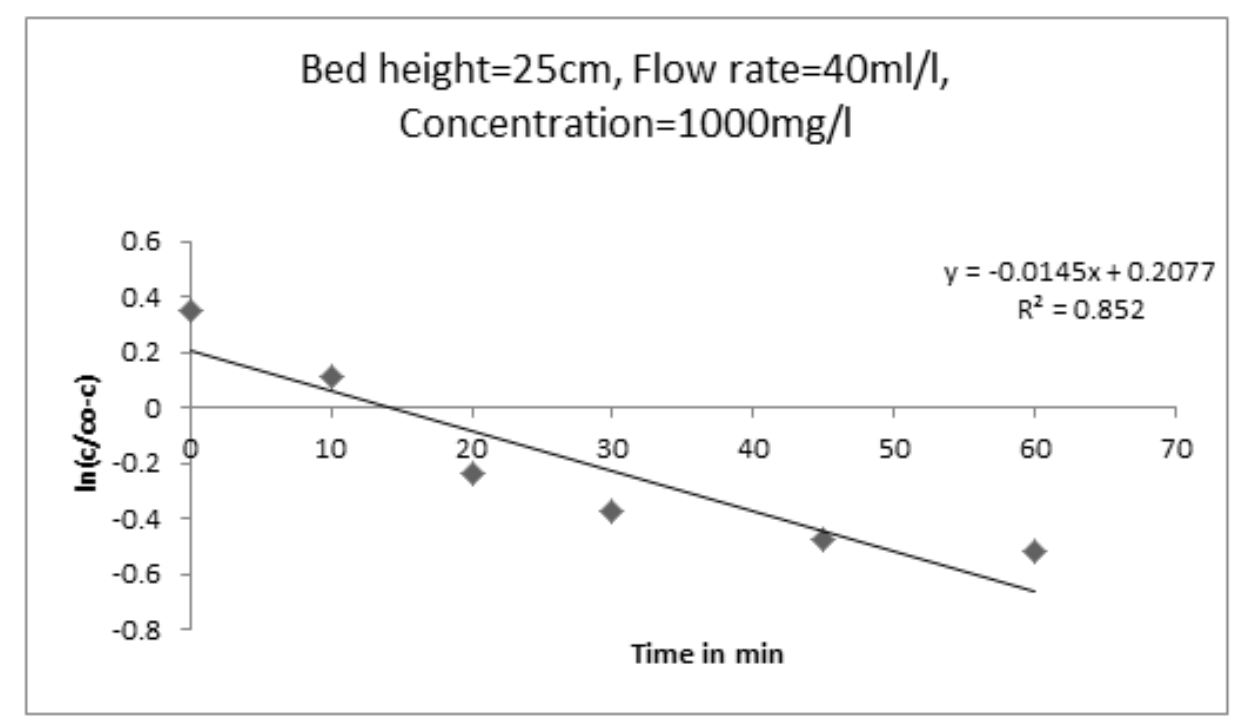

Fig4.5.5. Yoon \& Nelson Model for bed height of $25 \mathrm{~cm}$

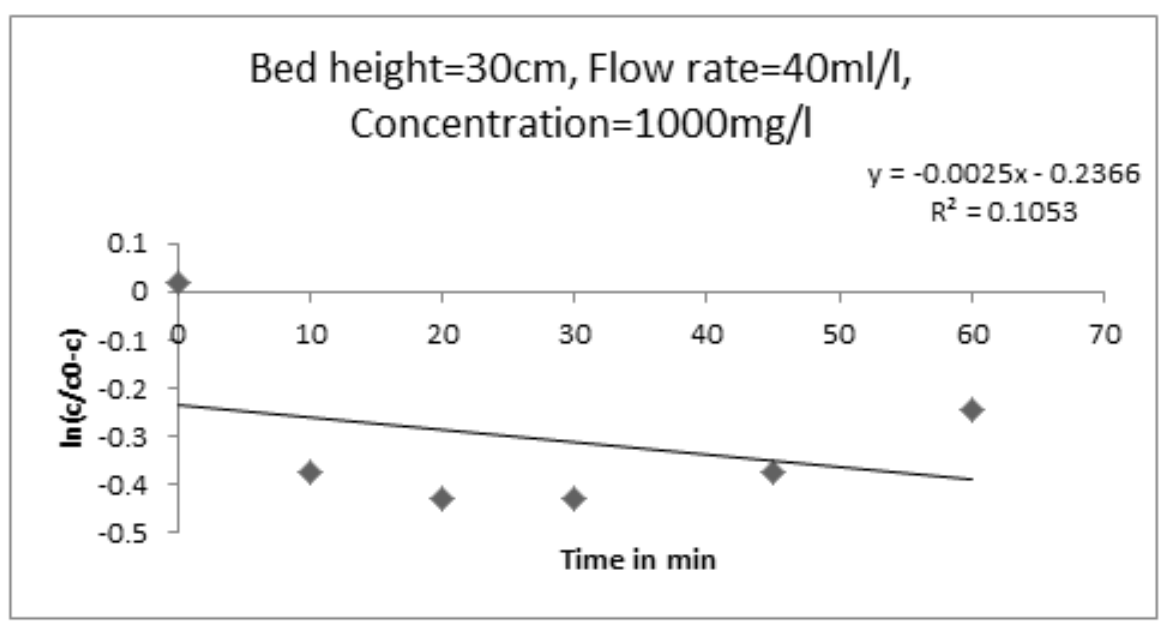

Fig4.5.6. Yoon \& Nelson Model for bed height of $30 \mathrm{~cm}$ 


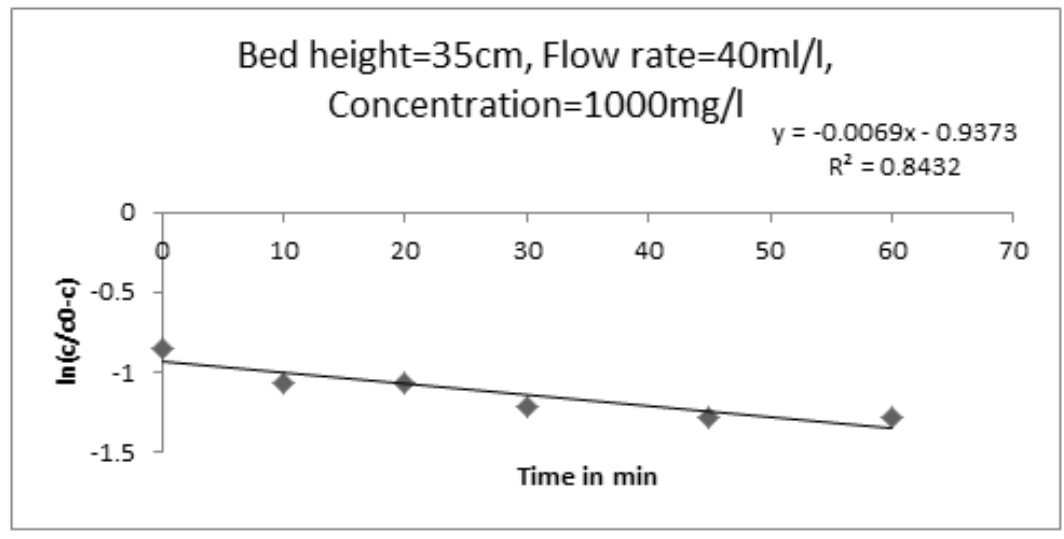

Fig4.5.7. Yoon \& Nelson Model for bed height of $35 \mathrm{~cm}$

\subsection{Effect of Bed Height (C/COvs. time)}

The effect of bed height on change in concentration of $\mathrm{Cr}$ with initialvalue was investigated by varying the bed height with a constant flow rate of $40 \mathrm{ml} / \mathrm{min}$. The initial bed height of column was kept $25 \mathrm{~cm}$. Series of experiments were undertaken by varying the bed height in the range of $(25-35 \mathrm{~cm})$ i.e. $25 \mathrm{~cm}$, $30 \mathrm{~cm}$ and $35 \mathrm{~cm}$. It has been found that as bed height increasesinitially capacity of removal of $\mathrm{Cr}$ was rapid further after saturationof bed it decreased. At bed height $35 \mathrm{~cm}$ initially, $\mathrm{C} / \mathrm{C}_{0}$ ratio was 0.298 at zero time, then it decreased to 0.256 at $20 \mathrm{~min}$, and reached point 0.217 at $60 \mathrm{~min}$.

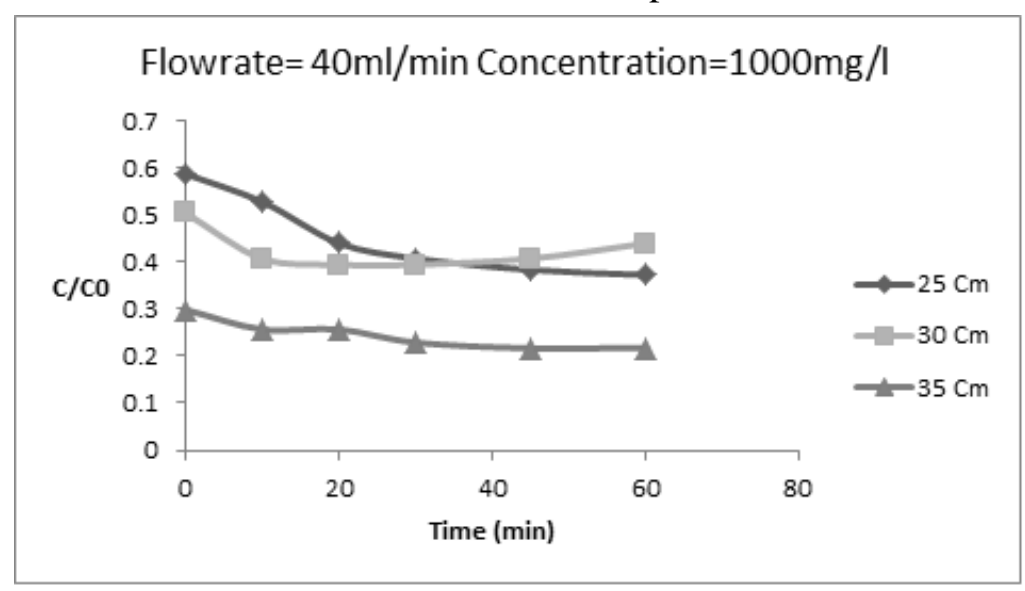

\subsection{Effect of Regeneration}

Fig4.6. Effect of Bed Height $\left(C / C_{0}\right)$

The rice husk used in packed bed was regenerated after it was saturated by treating it with $\mathrm{HCl}$. The same experiments were carried out to see the changes in removal capacity. Fig shows graph of removal of $\mathrm{Cr}$ with regenerated rice husk. Flow rate was fixed at $60 \mathrm{ml} / \mathrm{min}$ and bed height was kept $35 \mathrm{~cm}$ and the maximum removal was $56.73 \%$. Comparing with the removal of fresh batch of rice husk and regenerated rice husk, it has been found that the removal of $\mathrm{Cr}$ had reduced by $21.20 \%$

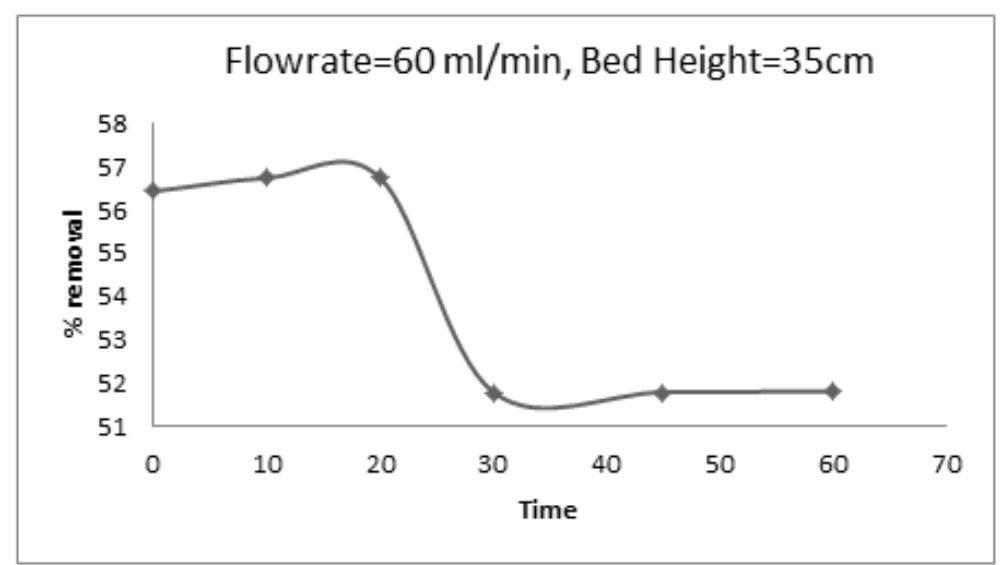

Fig4.7. Effect of use of regenerated rice husk on Cr adsorption 


\section{CONCLUSion}

A potential alternative for the removal of $\mathrm{Cr}$ (VI) from the aqueous solution has been found in the form of Activated Rice Husk, which is a low cost adsorbent. The curves obtained by carrying out the experiment gives a clear understanding that the breakthrough curves are the function of adsorption exhaustion rate and the fraction of unused bed length. It can be observed that by increasing the bed height \& concentration the breakthrough time was found earlier, whereas when the flowrate was decreased the breakthrough time was obtained earlier. The models were successfully checked with the theoretical \& experimental data obtained during the entire experiment. The values of model parameters are in agreement with similar work carried out for various metal ions and adsorbents. The experimental data also fits in both the models for different concentrations. The data of different bed heights and different flow rates fits well in Yoon and Nelson model. The adsorption capacity increased with bed height and initial concentration and decreased with flow rate.

\section{REFERENCES}

[1] Abia AA, Igwe JC (2005), Sorption kinetics and intraparticulate diffusivities of Cd, Pband $\mathrm{Zn}$ ions on maize cob. African Journal of Biotechnology 4: 509.

[2] O. E. A. Salam, N. A. Reiad , M. M. ElShafei , "A study of the removal characteristics of heavy metals from waste water by low-cost adsorbents", Journal of Advanced Research, II, pp 297-303,2011.

[3] El-Sharkawy EA (2001), Adsorption of textile dyes on to activated carbonssynthesized from solid waste: Decolourizing power in relation to surface properties. Adsorption Science \& Technology 19: 795-811.

[4] A.O. Dada, J. O. Ojediran, and A. P. Olalekan, "Sorption of Pb2+ from Aqueous Solution unto Modified Rice Husk: Isotherms Studies, Journal of Advances in Physical Chemistry", 2013, PP 1-6, 2013.

[5] Volesky B, Bohumil B (1990), Biosorption and biosorbents, in biosorptionofheavy metals. CRC Press, Boca Raton, Florida, pp: 3-5.

[6] Sathishkumar M, Jung SH, Song SH, Yun SI (2009), A novel method in utilization Of bokbunja seed wastes from wineries in liquid-phase sequestration of reactiveblue, International Journal of Environmental Research 3: $1-2$.

[7] Guo TO, Onukwuli DO, Olaitan SA, Atuanya CU, Akagu CC, et al. (2002) Effectof filler weight fraction on the mechanical properties of bambaragroundnut (okpa) husk polyethylene composite. International Journal of Current Research1714-1717.

[8] sNameni M, AlaviMoghadam M R and Arami M, (2008), "Adsorption of hexavalent chromium from aqueous solutions by wheat bran", International Journal of Environmental Science and Technology, 5(2): $161-168$.

[9] E. Malkoc and Y. Nuhoglu, "Potential of Tea Factory Waste for Chromium (VI) Removal from Aqueous Solu-tions: Thermodynamic and Kinetic Studies," Separation \& Purification Technology, Vol. 54, No. 2, 2007, pp. 291-298.

[10] American Public Health Association (APHA), "Standard Methods for the Examination of Water and Wastewater," 16th Edition, APHA, AWWA, WPCF, Washington, D.C, 1985.

[11] Sunil J. Kulkarni, Jayant P. Kaware."Packed Bed Adsorption Column Modeling for Cadmium Removal”,Int. J. of Thermal \& Environmental Engineering, Volume 9, No. 2 (2015) 75-82

[12] A. A. Ahmad and B. H. Hameed, "Fixed-bed adsorption of reactive azodye onto granular activated carbon prepared from waste," Journal of Hazardous Materials, vol. 175, pp. 298-303, 2010.

Citation: S. Kulkarni et al., "Modeling of Breakthrough Curves for Removal of Chromium from Waste Water", International Journal of Advanced Research in Chemical Science (IJARCS), vol. 5, no. 6, pp. 29-40, 2018. http://dx.doi.org/10.20431/2349-0403.0506005

Copyright: (C) 2018 Authors. This is an open-access article distributed under the terms of the Creative Commons Attribution License, which permits unrestricted use, distribution, and reproduction in any medium, provided the original author and source are credited. 